\title{
Designer nucleases to treat malignant cancers driven by viral oncogenes
}

\author{
Tristan A. Scott ${ }^{*}$ (10 and Kevin V. Morris
}

\begin{abstract}
Viral oncogenic transformation of healthy cells into a malignant state is a well-established phenomenon but took decades from the discovery of tumor-associated viruses to their accepted and established roles in oncogenesis. Viruses cause $\sim 15 \%$ of know cancers and represents a significant global health burden. Beyond simply causing cellular transformation into a malignant form, a number of these cancers are augmented by a subset of viral factors that significantly enhance the tumor phenotype and, in some cases, are locked in a state of oncogenic addiction, and substantial research has elucidated the mechanisms in these cancers providing a rationale for targeted inactivation of the viral components as a treatment strategy. In many of these virus-associated cancers, the prognosis remains extremely poor, and novel drug approaches are urgently needed. Unlike non-specific small-molecule drug screens or the broadacting toxic effects of chemo- and radiation therapy, the age of designer nucleases permits a rational approach to inactivating disease-causing targets, allowing for permanent inactivation of viral elements to inhibit tumorigenesis with growing evidence to support their efficacy in this role. Although many challenges remain for the clinical application of designer nucleases towards viral oncogenes; the uniqueness and clear molecular mechanism of these targets, combined with the distinct advantages of specific and permanent inactivation by nucleases, argues for their development as next-generation treatments for this aggressive group of cancers.
\end{abstract}

Keywords: Oncogenic viruses, ZFN, TALEN, CRISPR/Cas, HPV, Gammaherpesvirus, HTLV-1, MCPyV

\section{Background}

With the advent of genome editing came the notion and promise of next-generation therapeutics. Regardless of modality, designer nucleases function through a convergent mechanism by targeting a specific DNA site through a programmable binding component and then a nuclease component results in a double stranded break (DSB) at the target site forcing activation of repair pathwaysnon-homologous DNA end joining (NHEJ) or homology directed repair (HDR). Repair through NHEJ is errorprone and, under repetitive cleavage, results in insertion and deletions (indels) causing deleterious frame-shift mutations and gene inactivation, or two nucleases can be

*Correspondence: trscott@coh.org

Center for Gene Therapy, City of Hope, Beckman Research Institute and Hematological Malignancy and Stem Cell Transplantation Institute at the City of Hope, 1500 E. Duarte Rd, Duarte, CA 91010, USA used to precisely excise a section of DNA (Reviewed in [1]). HDR relies on a homologous DNA template to accurately repair the target site and through the introduction of an artificial template precise sequence changes to the genome can be made. For the purpose of gene inactivation, NHEJ is the most exploited pathway.

There are currently several gene-editing platforms used to target viral oncogenes: zinc finger nucleases (ZFN), transcription activator-like effector nucleases (TALEN), and the clustered regularly interspaced short palindromic repeats with CRISPR-associated protein (CRISPR/ Cas) (Fig. 1). Both TALENs and ZFNs exploit customizable DNA binding proteins fused to a FokI nuclease and, as the FokI is a heterodimer, requires two pairs of effectors targeted to opposite strands flanking the target site to reconstitute a functional catalytic FokI to generate a DSB. The binding modules of ZFNs are the Cys2His2 zinc finger proteins (ZFP) that each bind 3 base pairs of original author(s) and the source, provide a link to the Creative Commons licence, and indicate if changes were made. The images or other third party material in this article are included in the article's Creative Commons licence, unless indicated otherwise in a credit line to the material. If material is not included in the article's Creative Commons licence and your intended use is not permitted by statutory regulation or exceeds the permitted use, you will need to obtain permission directly from the copyright holder. To view a copy of this licence, visit http://creativecommons.org/licenses/by/4.0/. The Creative Commons Public Domain Dedication waiver (http://creativeco mmons.org/publicdomain/zero/1.0/) applies to the data made available in this article, unless otherwise stated in a credit line to the data. 


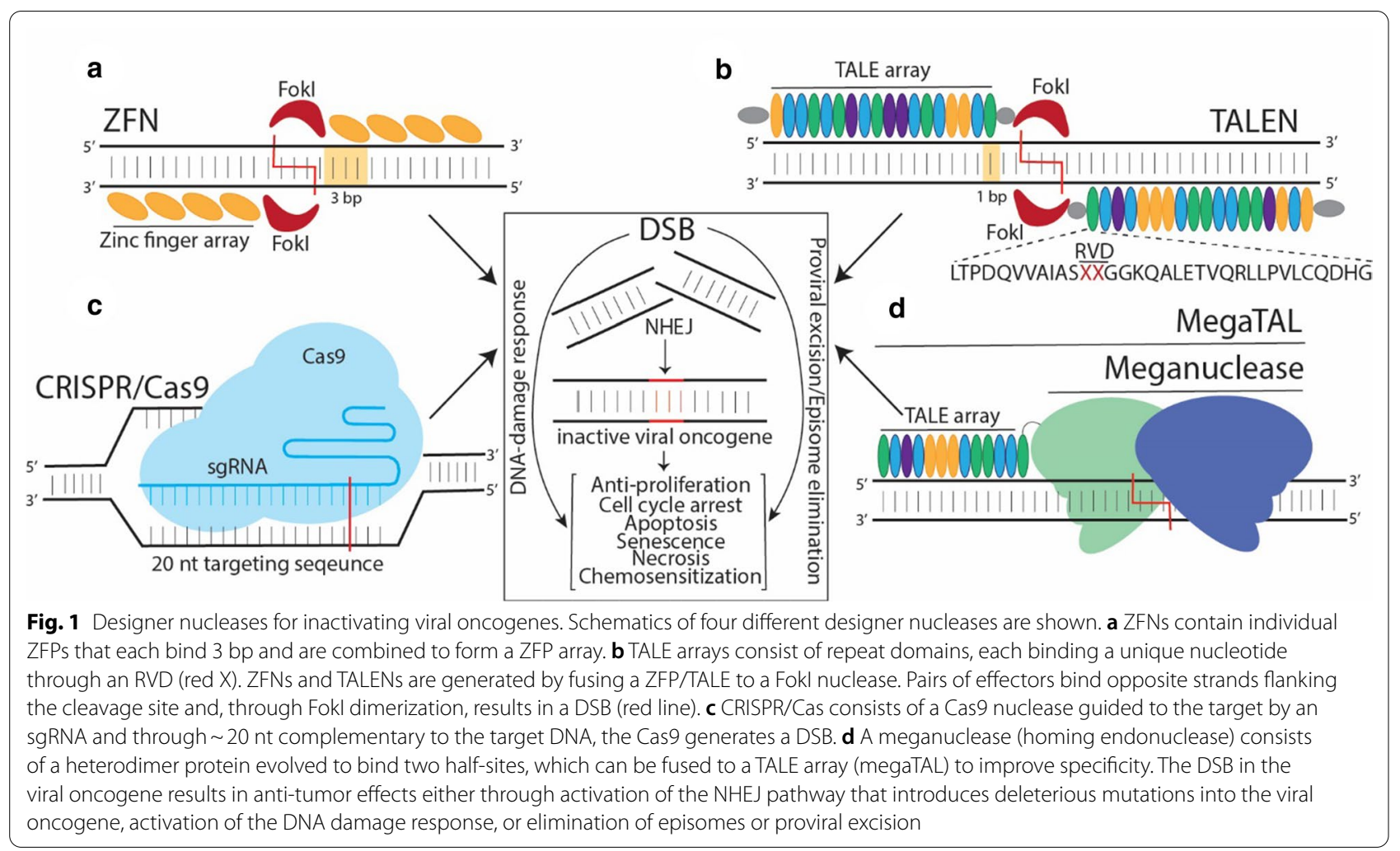

sequence, which can be assembled into arrays to recognize longer DNA sequences, although generating ZFN arrays involves complex methodology compared to the more modular assembly of TALENs. The TALEs DNA binding domains were identified as secreted proteins from the Xanthomonas spp. bacteria, and consist of highly conversed 33-35 amino acid repeats with two amino acid repeat-variable diresidues (RVD), which dictates individual nucleotide specificity (Fig. 1) [2]. Assembling repeats into TALE arrays flanked by essential TALE-derived $\mathrm{N}$ and C-terminal domains fused to FokI repurposes the system for genome editing [3].

CRISPR/Cas was discovered recently as part of the adaptive bacterial immune system and shown to be programmable to unique DNA sites [4], and was rapidly applied to mammalian genome editing [5]. The Cas9 system (class 2, type II) is an RNA-guided endonuclease that consists of a nuclease Cas9 interacting with a trans-activating RNA (tracrRNA) scaffold, which is directed to a target site by 20 nt complementary sequence in the CRISPR RNA (crRNA) flanked by the $3^{\prime}$ protospacer adjacent motif (PAM; Streptococcus pyogenes Cas9 ( $s p$ Cas9), PAM is $5^{\prime}$-NGG-3'), and extensive sgRNA:DNA complementarity results in Cas9 cleavage. The crRNA and tracrRNA can be expressed as a chimeric RNA joined by a tetraloop and referred to as a single/ small guide RNA (sgRNA) [6].
The ability to rationally design nucleases against a disease-causing DNA target represents an unprecedented level of precision in the treatment of disease, and designer nucleases have been applied to inactivate integrated and episomal viral DNA genomes, like in the case of human immunodeficiency virus (HIV) [7] and hepatitis B virus (HBV), respectively [8]. Furthermore, nucleases targeting various monogenetic targets are in clinical trials signifying the potential for the clinical translation of designer nucleases (Reviewed in $[9,10]$ ). There are many endogenous and environmental factors that result in the uncontrolled state of proliferation observed in cancer, but the notion that in some cancers a transmissible agent might play a role was paradigm shifting. Approximately $15 \%$ of cancers globally are caused by viruses [11]. Why oncogenic viruses result in cancer is a matter of debate as in most cases it's an evolutionary dead end for the virus, unable to produce progeny as a result of the truncation, integration, or epigenetic suppression of the viral genome. There are postulations that cancer is an unfortunate consequence of immune evasion by the virus, as a result of the overlap in proliferation and innate immunity pathways, which results in oncogenic transformation. This idea is supported by the fact that the majority of oncogenic viral infections are asymptomatic, and only a fraction of persist infections results in malignant transformation, 
which occurs decades after initial exposure to the infectious agent.

Known etiological viral agents associated with various cancers have been established (Table 1), and these viruses have been implicated not only in tumor formation and clonal expansion, but in the maintenance of the tumor state. These viruses encode 'oncoproteins' as well as the more recently explored 'onco-RNAs'-non-coding RNA or virally derived microRNAs (miRNAs) - that collectively target cellular factors to augment host cell survival, immune evasion, apoptotic pathways, and cell cycle progression for the purposes of viral persistence, but, ultimately, can result in oncogenic transformation. Oncogene addiction, the dependence of a cancer cell on a single gene, or a limited subset of genes, for survival has been described in some virus driven tumors, where tumor maintenance in entirely reliant on the viral oncogenes. However, it must be noted that oncogene addiction has only been formally proven in the context of human papillomavirus (HPV)-related cervical cancers, but there is significant evidence of other virus-associated cancers where the tumor phenotype is augmented by the presence of viral oncogenic elements.
This concept creates a basis for these viral oncogenes to be targets of therapeutic intervention and, specifically, targeted nucleases. Many oncoproteins are non-enzymatic making them 'undruggable', a feature immaterial for designer nuclease applications. Furthermore, targeted nucleases have a distinct advantage over other gene knockdown strategies like RNA interference (RNAi) or antisense oligonucleotides (ASO) as they result in permanent inactivation of the oncogene. This review explores potential oncogenic targets in virus-associated cancers, current nuclease modalities to these sites and potential alternative targets, as well as the challenges and considerations for the therapeutic development of designer nucleases.

\section{Human papillomavirus}

By far the oncogenic virus with the most developed platform of targeted nucleases is HPV, since a third of viral-associated cancers are caused by HPV [20]. As the causative agent of cervical cancer, the second most common cancer in woman and a leading cause of death in developing countries, it is responsible for approximately 450,000 new cases and 233,000 deaths per year

Table 1 Oncogenic viruses, associated malignancies and oncogenes

\begin{tabular}{|c|c|c|c|}
\hline Etiological agent & Malignancies and other disorders & $\begin{array}{l}\text { Targeted and potential } \\
\text { oncogenes }\end{array}$ & Review reference \\
\hline HPV & $\begin{array}{l}\text { Cervical cancer } \\
\text { Oropharyngeal cancer } \\
\text { Vagina cancer } \\
\text { Penile cancer } \\
\text { Anal cancer } \\
\text { Vulvar cancer }\end{array}$ & $\begin{array}{l}E 6^{a} \\
E 7^{a}\end{array}$ & {$[12,13]$} \\
\hline HTLV-1 & $\begin{array}{l}\text { Adult T-cell leukemia/lymphoma (ATL) } \\
\text { HTLV-1 associated } \\
\text { myelopathy/tropical spastic paraparesis (HAM/TSP) }\end{array}$ & $\begin{array}{l}\text { HBZ RNA } \\
\text { HBZ protein }\end{array}$ & {$[14]$} \\
\hline $\begin{array}{l}\text { EBV } \\
(H H V-4)\end{array}$ & $\begin{array}{l}\text { Burkitt's lymphoma (BL) } \\
\text { Hodgkin's lymphoma (HL) } \\
\text { Diffuse large B cell lymphoma (DLBCL) } \\
\text { NK/T cell lymphoma } \\
\text { Post-transplant lymphoproliferative disorders (PTLD) } \\
\text { Nasopharyngeal carcinoma (NPC) } \\
\text { Gastric carcinoma (GC) }\end{array}$ & $\begin{array}{l}\text { Latent coding } \\
\text { EBNA1 }{ }^{\mathrm{a}} \\
\text { EBNA2 } \\
\text { EBNA3A } \\
\text { EBNA3C } \\
\text { LMP1 }{ }^{\mathrm{a}} \\
\text { LMP2A }^{\mathrm{a}} \\
\text { Latent non-coding }^{\text {EBERs }} \\
\text { EBV miRNAs }\end{array}$ & {$[15,16]$} \\
\hline $\begin{array}{l}\text { KSHV } \\
(H H V-8)\end{array}$ & $\begin{array}{l}\text { Kaposi's sarcoma (KS) } \\
\text { Primary effusion lymphoma (PEL) } \\
\text { Multicentric Castleman disease (MCD) }\end{array}$ & $\begin{array}{l}\text { Latent coding } \\
\text { LANA }^{\text {a }} \\
\text { Kaposin } \\
\text { Viral cyclin (vCyclin) } \\
\text { Viral FLIP (vFLIP) } \\
\text { Latent non-coding } \\
\text { K12-miRNAs }\end{array}$ & {$[17,18]$} \\
\hline MCPyV & Merkel cell carcinoma (MCC) & 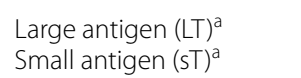 & [19] \\
\hline
\end{tabular}

Etiological agents with a list of their known associated cancers and other related disorders are shown. The genes that are the main oncogenic drivers of these cancers are highlighted as well as other potential targets for nuclease inactivation

a Studies inactivating the oncogene with designer nucleases 
with a low 5-year survival rate in the advanced stages of disease [21]. HPV is detected in over $95 \%$ of cervical cancer biopsies, a clear association, but there are many high-risk subtypes of HPV involved in other cancers such as anal and oropharyngeal cancers (Table 1) (Reviewed in [12]). Vaccination against high-risk subtypes is an effective strategy to prevent HPV-related cancers, but the high cost of the vaccine, low vaccine coverage in some countries, and the lack of anti-cancer effects within infected individuals suggests there will be HPV-related cancers in the foreseeable future, which urges the development of novel therapeutics.

\section{E6 and E7}

HPV is a non-enveloped virus with a $\sim 8 \mathrm{~kb}$ circular dsDNA genome, that infects the basal layer of the epithelium. Most individuals clear HPV within 2 years but if not cleared results in long-term persistence, a key feature in HPV-induced cancers [22]. Most HPV subgroups do not cause cancer, but the alpha papillomaviruses are associated with malignancies with the most common cancerassociated subtype being HPV16 followed by HPV18. The transformation of healthy cells to a tumor state has been extensively studied, and it is well understood that accessory proteins E6 and E7 are involved. The E6 protein causes the degradation of the tumor suppressor p53 and actives a common cancer-associated enzyme, telomerase, while E7 degrades the Retinoblastoma protein $(\mathrm{pRb})$ releasing the E2F family of transcription factors to active various downstream genes involved in cell cycle progression [13]. Integration of HPV is also an essential event in oncogenesis, a terminal event for HPV propagation, and normally occurs at fragile sites where the HPV episome is tethered to the host genome [23], inserting the long control region (LCR) promoter with the E6 and E7 genes. Out of the episomal context, E6/E7 expression increases resulting from the loss of LCR regulation by the viral E2 regulatory protein, and increased cellular proliferation, inactivation of cell-cycle check point inhibitors, genomic instability, and accumulative mutations in host genes results in cancer progression. Verification that these proteins are oncogenic drivers and possible therapeutic targets is that E6 and E7 together, or E7 alone, immortalize primary epithelial cells [24], causes epidermal and mucosa hyperplasia in transgenic mouse models [25], and gene knockdown results in inhibition of tumor growth in vitro and in vivo [26].

\section{Designer nucleases to HPV}

The first demonstration of CRISPR/Cas inhibiting HPVrelated cancers was sgRNAs targeted to HPV16's E6 and E7 proteins in the cervical cancer-derived $\mathrm{SiHa}$ cells, which increased p53 and it downstream factor, p21, resulting in reduced cell viability [27]. Furthermore, cells transfected with an anti-HPV CRISPR vector transplanted into mice reduced tumor volume and size. The authors also designed a sgRNA to the LCR promoter, which inhibited both E6 and E7 expression and enhanced tumor volume reduction in vivo, representing a compact approach to inhibit both genes through promotor inactivation. Anti-tumor CRISPR/Cas activity against other subtypes was explored through targeting E6 and E7 in the HPV18-transformed Hela cell line resulting in reduced viability through activation of $\mathrm{p} 53$ and, important to this study, pRb upregulation that caused cell cycle arrest [28], verifying that both high-risk subtypes could be inhibited using targeted nucleases.

HPV cell lines have an irregular number of integrated copies from 1-2 copies/cell in SiHa cells to $\sim 500$ copies/ cell in CaSki cells [29], which may be an issue for effective target inactivation. However, targeting the HPV16 E7 gene showed similar induction of apoptosis, reduction in viability and $\mathrm{pRb}$ activation in both cell lines [30], which suggests integrated copy number is not a factor. As it is unlikely that all copies in CaSki cells were inactivated, DSB may be sufficient to active proapoptotic pathways, and anti-tumor effects are not strictly limited to oncogene mutation, which has been suggested by others [28] (Fig. 1). Also, this suggests that even a momentary reversal of the "oncogenic amnesia" perpetrated by the viral oncogenes [31] - a model purposing that the tumor cell is oblivious to its state of genomic insult-is enough to restore checkpoint inhibition and halt tumorigenesis. However, the contribution of individual integrations to tumorigenesis in CaSki cells has not been determined, and only a subset may need to be inactivated, which could also explain the similar inhibitory profiles.

The above studies represent cervical cancer cell lines, but HPV causes a range of malignancies (Table 1). Whether other HPV-related cancers could also be inhibited by targeted nucleases was explored using CRISPR/ Cas inactivating an HPV18 E6 gene in an oral squamous cell carcinoma, HSC-2, and resulted in reduced proliferation with increased apoptosis [32]. Targeting of HPV16 in an oropharyngeal squamous cell carcinoma, SCC2, was explored, but inactivation of E7 alone was insufficient to affect cell survival and required CRISPR targeting of both E6 and E7 to reduce viability by 50\% [33]. Other studies targeted E7 in other subtypes, HPV6 and 11, which are low-risk wart causing cancers in primary keratinocytes and observed reduced viability [34]. These studies provide evidence that targeted nucleases could be generally applied to inhibit HPV-induced tumors.

Delivery remains a significant hurdle for any gene therapy, and programmable nucleases are no exception. Various viral vectors can be used to deliver and express 
transgenes, but a commonly exploited vector is the adeno-associated viral vector (AAV). AAV-2 was used to deliver a E6 sgRNA, albeit to HPV cell lines overexpressing Cas9, and when administrated intratumorally to subcutaneously implanted tumors in mice, it reduced tumor size and volume [32]. Although viral vectors are a promising vector for gene therapy, limitations in targeting viral oncogene with designer nucleases exist, which is discussed below (see Delivery).

Promising non-viral vector approaches have been explored to deliver anti-HPV designer nucleases. Early stage HPV cervical intraepithelial neoplasia 1 or 2 (CIN1/2) are usually treated by cauterization or excision, but these methods are associated with increased risk of miscarriage and premature birth. The HPV neoplasm can return, and recurrent HPV is associated with a higher risk of cervical cancer. Another delivery approach focused on local vaginal administration to inactivate early stage HPV cancers. Hu et al. [35], developed a series of paired TALENs to target E6 and E7 genes in HPV16 and 18. Optimized through N-terminal domain truncations and FokI mutations, the best TALENs resulted in increased apoptosis and reduced cell growth in vitro and tumor inhibition in transfected tumors in vivo. Furthermore, the HPV16 E7 TALENs were delivered using a cationic polymer intravaginally to K14-HPV16 transgenic mice. Local delivery almost completely inactivated the E7 protein with a concordant reduction in hyperplasia and reversal of the malignant phenotype in the cervix. Furthermore, proliferation markers were reduced with restoration of $\mathrm{pRb}$ levels and cell cycle regulatory factors. No lymphocyte infiltration resulted from TALEN treatment suggesting no immune response to the bacterially derived TALE components, and collectively this provides strong support for a minimally invasive and effective means to inactive early stage HPV cervical cancers. Ding et al. [36], verified ZFNs as an anti-HPV tumor modality targeting E7 in HPV16 and 18. The ZFN were bound to a cationic polymer and injected into HPV-associated tumors, which increased apoptosis markers while reducing tumor size and proliferation markers, and likewise could be used in local and topical applications. The cationic polymer represents a means for local delivery of designer nucleases but is not likely viable for systemic administration.

One of the most developed delivery systems was a recent study by Jubair et al. [37], who used a Cas9 and E7-sgRNA vector loaded into 'stealth' liposomes. These are lipid nanoparticles that are PEGylated to prevent opsonization, increase circulation time and stability while reducing toxicity. Systemic delivery of the CRISPR components to the tumor occurred through 'passive targeting' resulting from higher retention in tumors from increased angiogenesis and permeability. Administrated intravenously, inhibition of subcutaneous tumor volume was observed with increased apoptosis and mouse survival. Impressively, the remaining benign nodule was negative for p16, an upregulated marker in HPV-tumors, suggesting effective eradication of the oncogenic drivers.

Purified protein may also be a form in which to prepare therapeutic recombinant nucleases to inactive HPV. Novel HPV promoter targeting modalities have been developed using the bovine HPV E2 fused to FokI (BEF) [38], but this system suffered from poor cleavage and mostly suppressed the promoter through E2 protein binding. However, expanding upon this concept, Miro et al. [39], developed an artificial zinc finger (AZP), a single ZFP targeted to the E2 binding site in the HPV 18 promoter, which was fused to either a Staphylococcal nuclease (SNase) [40], or an optimized single-chain FokI dimer (scFokI) [41, 42], and this compact nuclease platform is capable of generating DSBs without the need for two ZFN effectors. Furthermore, ZFPs are intrinsically cell permeable proteins [43] and when fused to cell penetrating peptides (CPP) $[44,45]$ could facilitate direct internalization of the recombinant nuclease. When the CPP-modified AZP-SNase was applied directly to cells it was able to inhibit an HPV replication vector [40, 46]. Unfortunately, the authors did not show anti-tumor effects in any HPV-transformed cell lines, but nevertheless it is conceivable that direct application of cell-penetrating recombinant protein could also be applied for the local treatment of HPV.

Inactivating viral oncogenes can result in anti-tumors effects through apoptosis, necrosis, or senescence. A preprint manuscript that targeted HPV18 E6 and E7 genes with CRISPR/Cas explored the anti-tumor mechanisms [47], and, contrary to other studies, apoptotic features were no present but instead markers of senescence were observed. Shankar et al. [48, 49], tested TALENs to HPV16 E7, and observed a distinct lack of apoptosis, but instead features of cell cycle arrest and necrosis. Collectively, these studies show that a pleiotropic route to tumor inhibition occurs upon oncogene inactivation in HPV-related cancers.

\section{Human T-cell leukemia virus type 1}

Human T-cell leukemia virus type 1 (HTLV-1) is a retrovirus that has a broad global distribution and has infected $\sim 10$ million people through sexual contact, mother-to-child transmission, or blood exposure of which $2-5 \%$ will develop malignancies [14]. It forms a life-long infection within individuals through proviral integration into the host genome with a notable tropism for its primary cell of transformation, $\mathrm{CD}^{+} \mathrm{T}$-cells. Although most people will be asymptomatic, after a long latency period ( $>30$ years) HTLV-1 infection can result 
in a devastating cancer, adult T-cell leukemia/lymphoma (ATL), where in its most common form of acute ATL the median survival from diagnosis is $\sim 9$ months even with aggressive treatment [50], urging the development of alternative therapeutic strategies.

\section{HBZ}

The $\sim 9 \mathrm{~kb}$ HTLV-1 proviral genome is flanked by $5^{\prime}$ and $3^{\prime}$ long terminal repeat (LTR) promoters, which can transcribe notable non-structural oncogenes from the $5^{\prime}$ and $3^{\prime}$ LTRs, the Tax and HTLV-1 bZIP factor (HBZ) genes, respectively. Transformation results from a complex interplay between these two proteins, and Tax's transformative contributions to ATL are extensively studied (Reviewed in [14]). Although undoubtedly important in oncogenic transformation, Tax is highly immunogenic resulting in immune clearance and, in ALT, Tax is almost always inactivated through truncation, mutation or epigenetic suppression of the $5^{\prime}$ LTR $[51,52]$, questioning its role as ATL's main oncogenic driver.

The discovery of the anti-sense HBZ transcript [53] has sparked elucidation of its role in oncogenic transformation, maintenance as well as pathological features of the disease. The non-immunogenic HBZ is expressed in all ATL patient-derived tumors $[54,55]$ and activates pro-survival genes [56], supports proliferation [57-59], upregulates $\mathrm{C}-\mathrm{C}$ chemokine receptor 4 (CCR4), a distinct marker of ATL that augments ATL migration and proliferation [60], causes bone degeneration through RANKL/c-Fos pathways [61], is anti-apoptotic [62], upregulates telomerase [63], and promotes genomic instability through cellular miRNAs [64]. Importantly, transgenic mice expressing HBZ develop T-cell malignancies [65], and inhibition of HBZ in HTLV-1 transformed cell lines reduces proliferation [66], highlighting $\mathrm{HBZ}$ as a potential oncogenic target in ATL for nuclease-mediated inactivation. Interestingly, both the HBZ mRNA and protein have distinct functions [56], suggesting that inhibiting both the protein and RNA may be required to augment HBZ-mediated effects.

\section{Designer nucleases to HTLV-1}

Currently, only one study has targeted the LTR using ZFNs, which reduced proliferation in various HTLVtransformed and patient-derived ATL cell lines, and reduced tumor volume in mice [67]. The HBZ-specific effects of ZFNs were not investigated, and inhibition could result from several possible mechanisms, (1) mutation of transcriptional regulatory elements in the LTR affecting HBZ expression, (2) excision of the proviral genome, including HBZ, by cleaving the flanking LTRs, or (3) apoptosis through activation of DNA damage responses (Fig. 1). A more focused strategy could target the early HBZ coding sequence as the RNA structure that supports proliferation has been elucidated [57], resulting in inactivation of both the RNA and protein functions of HBZ. With a clear molecular target and demonstrated efficacy, further development of targeted nucleases to HTLV-1 should be considered as a treatment strategy for ATL.

\section{Gammaherpesviruses}

The Gammaherpesvirinae subfamily includes the first human oncovirus discovered, Epstein-Barr virus or human herpesvirus-4 (EBV/HHV-4), and Kaposi's sarcoma-associated herpesvirus (KSHV/HHV-8), which are membraned viruses with large dsDNA genomes of $\sim 170 \mathrm{~kb}$. EBV is a common, persistent infection present in $\sim 95 \%$ of humans and results in $\sim 1 \%$ of all cancers consisting of lymphoid and epithelial malignancies, the most common being B-cell lymphomas and nasopharyngeal carcinoma (NPC) (Table 1). KSHV infection occurs at a young age in endemic areas or transmitted by oral shedding and bodily fluids, but rarely causes disease in healthy individuals. KSHV malignancies generally occur in immunocompromised individuals epidemiologically linked to the early days of the AIDS pandemic, or in induced immune suppression such as an organ transplant. It infects a wide range of epithelial and immune cells and is the etiological agent of the epithelial-derived Kaposi's sarcoma (KS) (Table 1), and other lymphoproliferative disorders, like primary effusion lymphoma (PEL), a rare neoplasm with a median survival of 1 year. Although incidences of KS have reduced with antiretroviral therapy (ART), half of the AIDS-related KS cases never achieve remission with no known cure [68], and is associated with significant mortality in developing countries [69].

\section{Latency-associated genes}

EBV and KSHV have multicopy circular genomes present in the nucleus, which rarely integrates, and exists as episomes tethered to, and copied with, the host DNA. Herpesviruses have lytic and latent states, but oncogenesis is generally associated with latency. The latent genome encodes a range of latency coding and non-coding RNAs that play a role in immune evasion, enhance survival and cycle cell progression, manipulate cell signaling as well as control viral latency (Table 1) [15]. Unlike the relativity few oncogenes in other virusassociated cancers, herpesviruses have a concert of elements that contribute to episome stability and oncogenesis, which could be noteworthy targets for designer nucleases. 


\section{Designer nucleases to EBV and KSHV}

The oncogenic ability of EBV is clearly established as it can transform its main cell type, B lymphocytes, in vitro [70], and the presence of EBV provides a survival advantage to the tumor cell [71]. The EBV genome encodes a wide range of factors that promote tumorigenesis, so strategies have focused on the eradication of the EBV genome through either nuclease-mediated cleavage and degradation, or targeting viral proteins involved in episome maintenance. After EBV infection, the genome progresses through a series of latency programs with an ever-reducing number of expressed genes, but EBV nuclear antigen 1 (EBNA1) is common to all latency states. Apart from its roles in immune evasion and oncogenesis [72], EBNA1 is essential for the persistence of the viral genome as inhibitors reduce the genome copy number [73] and EBNA1 depletion inhibits tumor proliferation [74-76], making it a rational anti-tumor target.

However, the anti-proliferative effects of inactivating EBNA1 or genomic depletion in several studies has either been difficult to achieve, or not characterized for anti-tumor effects. Noh et al. [77], targeted EBNA1 with TALENs, which required multiple treatments and clonal expansion to observe reduced proliferation in the edited clones. Nevertheless, reduced clonal outgrowth was observed in EBNA1 'low' clones in two lymphocyte and one gastric tumor cell lines, demonstrating proof-of-concept that inactivating EBNA1 with nucleases could suppress a range of EBV malignancies. Wang and Quake [78], used CRISPR/Cas with seven sgRNAs targeted to numerous repeat sequences simultaneously in order to increase the likelihood of episome fragmentation. Large deletions were observed in enriched cell populations resulting in an induction of apoptosis and an $85 \%$ reduction in viral genome copy number. Others have also confirmed the reduction in EBV copy number when targeting EBNA1 and oriP (the EBNA1 binding site in the episome), and a combination of sgRNAs were needed for high-level episome eradication (up to 95\%), but anti-tumor effects were not studied [79]. Another study targeting EBNA1, oriP and W repeats with multiple sgRNAs in NPCs reduced EBV DNA up to 50\%, but did not reduce viability, which might reflect issues with observing effects in bulk cell populations and an episome 'eradication threshold' for anti-tumor effects [80]. In KSHV, latency-associated nuclear antigen (LANA) is likewise involved in episome maintenance, suppresses p53 [81] and pRb [82], and its knockdown resulted in KSHV episome reduction and apoptosis in PEL cells [83]. CRISPR/Cas was tested against LANA and delivered using a replication-incompetent adenovirus type 5 (Ad5) as a viral delivery platform [84]. Immortalized cell lines subsequently infected with KSHV were treated with the Ad5-CRISPR vector, which reduced LANA protein and nearly eradicated the episomes. As the cell lines were not KSHV-dependent, effects on growth could not be observed, but may be a promising approach to deplete KSHV genomes. The loss of genomes was also observed when engineering CRISPR knockouts of the ORF57 gene in PEL cells [85], which further suggests that simply targeting the episome could result in nuclease-mediated degradation (Fig. 1). Nevertheless, virus genome depletion as an anti-tumor strategy in KSHV and EBV requires significantly more characterization as it's unclear if this represent a viable approach.

Both EBV and KSHV tumors have numerous episome copies but, unlike in HPV-associated tumors, the copy number may be a hurdle for complete herpesvirus eradication. Inactivating essential oncogenes may better mitigate the malignant phenotype in the event of incomplete genomic elimination. Latent membrane protein 1 (LMP1) is an established oncogene [15] and, if inhibited, results in cell cycle arrest [86]. Overexpressing LMP1 promoted cell growth that was inhibited by anti-LMP1 sgRNAs [87], suggesting this could happen in the context of an EBV-dependent tumor and should be explored further as a target. In KSHV, viral FLIP (vFLIP) and viral cyclin (vcyclin) genes are part of the KSHV oncogenic latency cluster [88] (Table 1), and knockdown reduced PEL tumor growth in vitro and in vivo [83], highlighting these genes as possible targets for future studies. Alternatively, the majority of PELs are co-infected with EBV and EBNA1 inhibition reduced KSHV-dependent cell line proliferation [89], opening up the possibility of combined therapeutics for EBV and KSHV in dually infected cells.

In leu of protein coding genes, a variety of non-coding RNAs are expressed from the latent herpesvirus episome. MiRNAs are small non-coding RNAs that regulate target genes through RNA silencing, and KSHV encodes an important K12 cluster of miRNAs (K12-miR) involved in tumorigenesis, immune evasion, and maintenance of latency (Reviewed in [17]). Liang et al. [90], targeted and excised the miRNA promoter in PEL cell lines and showed that the miRNA levels were reduced with a concordant increase in viral lytic genes. Notably, treated cells proliferated slower and reversed the inhibitory effects of the miRNAs on their cellular cell cycle and signaling targets. EBV has a multitude of viral miRNAs expressed during latency that are involved in oncogenesis (Reviewed in [16]), and inactivation of EBV miRNAs inhibited cell growth in vitro [91]. CRISPR sgRNAs that excise the EBV miRNA promoter have been shown to mitigate the miRNA's inhibition of their cognate targets [79], and should be explored further to inhibit EBV-dependent proliferation, which may serve as more rational anti-tumor target than 'brute force' genomic eradication. 
There are significant challenges for targeting herpesvirus-associated malignancies with designer nucleases. Current targets lack efficacy in bulk populations or antiproliferative effects in relevant cell models. Importantly, there are no in vivo studies confirming the anti-tumor effects of targeted nucleases for these herpesvirus-associated cancers. Furthermore, whether the anti-proliferative effects observed in KSHV PEL cells will translate into KS or multicentric Castleman disease (MCD) remains to be determined, but the lack of KS cell lines is a hindrance. As mentioned, there are a large number of episomes that would need to be effectively eradicated (up to 800 copies in some NPCs [92]), and the extent of genome eradication needed to get an inhibitory effect is currently unknown and strongly urges further characterization, or the identification of more discrete anti-tumor targets.

\section{Merkel cell polyomavirus}

Merkel cell polyomavirus (MCPyV) is the most recently discovered oncogenic virus [93] and is ubiquitously present in the human population as it is acquired in the first years of life, and generally does not cause any symptoms. Polyomaviruses have long been known to transform cultured cells (SV40) [94], but it was many years before $\mathrm{MCPyV}$, the first human oncogenic polyomavirus agent, was found in $80 \%$ of Merkel cell carcinomas (MCC), a rare and aggressive skin cancer [93]. MCC occurs in immunocompromised individuals, but mostly in the elderly with a median diagnosis age of $\sim 70$ years old [95], but with a $95 \%$ increase in MCC diagnoses since 2000 [96] and a 5-year mortality rate of $>40 \%$, makes it an aggressive skin cancer in need of therapeutic solutions.

\section{LT and sT}

The reason for oncogenic transformation is still being elucidated but, like HPV, integration of MCPyV is required. $\mathrm{MCPyV}$ is a non-enveloped, circular dsDNA virus about $\sim 4 \mathrm{~kb}$ and in MCC there is the monoclonal integration of the tumor antigen (TA) open reading frame, which expresses the large (LT), small (sT), $57 \mathrm{kt}$, and ALTO transcripts [97]. Truncation of the LT is required, which importantly disables viral replication domains, but retains $\mathrm{pRb}$ interactions for cell cycle regulation; both features needed for oncogenesis [98, 99]. The oncogenic involvement of the $57 \mathrm{kt}$ and ALTO proteins are not well understood, but sT, a part from increasing LT expression [100], promotes oncogenesis through cap-dependent translation [101], functionally inhibits p53 [102], and is a main oncogenic driver as it alone can transform rat fibroblasts [101], co-operates with LT to promote growth in human fibroblasts [98], and generates carcinomas in transgenic mice [103]. Unlike LT, sT is present in all MCPyV-positive MCCs [101], but even though sT knockdown has similar growth inhibition to a combined suppression of LT and sT, its reduction alone did not affect cell cycle progression or cause apoptosis [101], suggesting inhibition of both oncogenes would be beneficial for anti-tumor effects. Furthermore, knockdown studies have shown that MCCs are TA-dependent in vitro [104] and in vivo [105] verifying these oncogenes as possible targets for nuclease-mediated inactivation.

\section{Designer nucleases to MCPyV}

CRISPR/Cas sgRNAs targeting the LT or a common sT/ LT site were tested in a patient-derived MCC cell line, which resulted in reduced proliferation with cell cycle arrest, apoptosis, and necrosis [106]. In exploring the mechanism in more detail apoptotic markers were not present, but the reestablishment of various cell cycle regulatory features was observed, which has been noted by others [104], and likely a result from reactivation of the $\mathrm{pRb}$ pathway [105]. These results are promising and future work should confirm these effects within in vivo models.

\section{Targeted nucleases and chemosensitization}

Viral oncogenic drivers can offer pro-survival advantages to tumor cells, which can diminish the effects of chemotherapy. ATL is refractory to conventional chemotherapy and HBZ activates the brain-derived neurotrophic factor/TrkB signaling pathway, a pro-survival pathway implicated in chemoresistance [107]. Furthermore, Survivin, an inhibitor of apoptosis and also associated with chemoresistance, is upregulated by many of the mentioned viral oncoproteins [56, 108-110]. This chemosensitization through nuclease-mediated inactivation of viral oncogenes was demonstrated when Zhen et al. [111], showed in vitro and in vivo that CRISPR/Cas9 targeting of HPV E6 and E7 improved the toxic effects of cisplatin and EBV-sgRNAs to EBNA1 increased tumor sensitivity to cisplatin and fluorouracil [80], suggesting targeting viral oncogenes could improve responses to traditional chemotherapeutic agents.

\section{Nuclease escape and oncogenic virus variation}

Evolving targets, like viruses, can escape targeted treatment. However, the replicating factors of oncogenic viruses are either epigenetically suppressed (EBV/KSHV) or lost due to integration and inactivation (HPV, HTLV$1, \mathrm{MCPyV}$ ), and so the likelihood of virus-induced escape is relatively low. Variation within the genomically unstable cancer cell may also select for escape mutants, but as a result of the clonal expansion of many virally-driven tumors, this may not be an issue $[14,93,112]$. "Nucleasemediated escape" results from the introduction of NHEJ mutations that are tolerated within the oncogenes (silent 
mutations/in-frame deletions), but prevents nuclease re-cleavage, which has been observed in CRISPR/Cas9 targeting of HIV [113] as well as herpesviruses [79]. It must be noted in the case of HPV, tumor suppression improved with repetitive doses in vivo resulting in complete oncogene eradication arguing against this type of escape in the context of HPV [37]. Nevertheless, this escape arises in type II Cas9 systems because the cleavage site is over the crucial binding nucleotides in the sgRNA, the 'seed' sequence, which is intolerant of the introduced mutations. "Nuclease-mediated escape" can be avoided by using multiple sgRNAs [79, 114], or by exploring other CRISPR types. In the type V Cas12 system, the 'seed' sequence is distal to the cleavage site and the crRNA is more tolerant of the introduced mutations favoring re-cleavage and ensuring target site inactivation, a feature leveraged to great effect in the complete inhibition of HIV escape mutants with a single Cas 12 crRNA [115]. Of note, this escape may not be an issue for ZFNs or TALENs as their binding sites flank the cleavage site, but this eventuality remains to be assessed.

Oncogenic viruses have a wide range of strains and subtypes and, in some cases, significant sequence variation. Some viruses, like HTLV-1, are highly conserved even amongst geographically distant subtypes [116], but the HPV E6 and E7 genes are poorly conserved making each targeted nuclease HPV subtype-specific (Reviewed in [12]). This variability may necessitate multiple targeted nucleases to effectively treat a broad range of viral subtypes. The easily programmable nature of CRISPR/Cas technology may be better suited for multiplex targeting, where pools of Cas9 sgRNAs could be utilized. Alternatively, exploiting features of the Cas 12 CRISPR system, which uses compact arrays of pre-crRNAs processed by the Cas12 enzyme into a series of mature crRNAs [117], is potentially capable of targeting multiple oncogenic subtypes simultaneously. Nevertheless, targeting highly conserved regions should be an upfront factor in nuclease design to ensure its broader therapeutic applicability.

\section{Specificity}

Specificity of the targeted nucleases is paramount as offtarget DSBs in the genome of healthy cells could result in tissue and organ damage or even cancer, and many of the mentioned studies were lacking in considerations towards specificity (Table 2). The topic of designer nuclease specificity has been covered extensively (Reviewed in $[118,119])$, and so, briefly, as a result of the rational design of targeted nucleases, off-targeting can be mitigated, or at least thoroughly quantified, for the following reasons: (1) TALENs and ZFNs use an obligate FokI heterodimer and this 'two-part' requirement to generate DSBs has built-in specificity, (2) designer nucleases can be bioinformatically screened for low off-target profiles within the human genome, (3) Cas9 specificity can be improved by using rationally engineered or evolved highfidelity Cas9 mutants, or, similar to the 'two-part' recognition of the ZFN/TALEN systems, use a nickase Cas9 or a catalytically dead Cas9 fused to FokI that requires two adjacent sgRNAs to generate DSBs, (4) truncation of the sgRNA (tru-sgRNA) can improve its specificity by removing nonessential nucleotides, (5) using the nucleases in more transient forms such as mRNA or a ribonucleoprotein (RNP) will prevent long-term persistence of the nuclease, which is associated with higher off-target effects, (6) the off-target profile of designer nucleases can be objectively quantified and qualified through an extensive array of unbiased assays in vitro and in vivo, and (7) the viral oncogene represents a unique target that is not present in the human genome. Nevertheless, targeted nucleases towards oncogenic viruses should be thoroughly vetted prior to therapeutic applications.

\section{Delivery}

Delivery of designer nucleases to tumor cells remains a significant challenge for its therapeutic application. The type of delivery system used will be dictated by the cancer type, stage of cancer, whether local or metastatic, and the involvement of secondary tissues. Careful consideration would need to be given to the selection of a delivery system that best suits the malignancy. Currently, delivery approaches are underdeveloped (Table 2). Two studies used viral delivery vectors, AAVs [32] and Ad5 [84], which may be compatible with local delivery. However, viral vectors have several limitations: (1) The repeat sequences present in ZFPs and TALEs make the engineering and production of viral vectors significantly more difficult, (2) the $s p$ Cas9 systems preclude the use of AAVs due to the limited packaging capacity of this vector $(\sim 4.4 \mathrm{~kb}$ for double-stranded AAVs), but could be used with smaller orthologues like Staphylococcus aureus Cas9 (saCas9) [120], Campylobacter jejuni (cjCas9) [121], or the smallest Cas variant discovered in 'huge' phages Cas12 $\phi$ [122], (3) the long-term expression of nucleases in tissues other than the tumor is not desirable potentially increasing off-targeting in these tissues or may elicit cytotoxic cellular responses to the bacterial transgene components, and (4) antibody responses to the viral vector would preclude repeat administration. Overall, these limitations suggest non-viral systems may be more applicable for the delivery of targeted nucleases to virally driven cancers.

As discussed, cationic polymers [35] or cell-penetrating proteins [46] could work well for local injection into accessible solid tumors, but unlikely to be compatible with systemic delivery. Nevertheless, these are 
Table 2 Targeted nucleases to oncogenic viruses

\begin{tabular}{|c|c|c|c|c|c|c|c|}
\hline Viral target & Modality & Target & Cell lines & In vivo & Vector & Delivery method & Reference \\
\hline \multirow[t]{12}{*}{ HPV } & \multirow{7}{*}{$\begin{array}{l}\text { spCas9 or dspCas9- } \\
\text { Fokl }\end{array}$} & E6, E7, LCR & $\mathrm{SiHa}$ & Yes & Plasmid DNA & No & {$[27,111]$} \\
\hline & & E6, E7 & Hela, SiHa & No & Plasmid DNA & No & {$[28]$} \\
\hline & & E7 & $\mathrm{SiHa}, \mathrm{CaSki}$ & No & Plasmid DNA & No & {$[30]$} \\
\hline & & E6 & Hela, HSC-2, SKG-I & Yes & AAV genome & $\begin{array}{l}\mathrm{AAV}-2^{\mathrm{a}} \\
\text { (intratumoral) }\end{array}$ & [32] \\
\hline & & E6, E7 & Hela, CaSki & Yes & Plasmid DNA & $\begin{array}{l}\text { 'Stealth' Liposomes } \\
\text { (Intravenous) }\end{array}$ & {$[37]$} \\
\hline & & E6, E7 & Hela & No & Plasmid DNA & No & {$[47]$} \\
\hline & & E6, E7 & scc2 & No & Plasmid DNA & No & [33] \\
\hline & \multirow[t]{2}{*}{ TALEN } & E6, E7 & SiHa, S12, Hela & Yes & Plasmid DNA & $\begin{array}{l}\text { Cationic polymer } \\
\text { (Topical) }\end{array}$ & {$[35]$} \\
\hline & & E7 & $\mathrm{SiHa}, \mathrm{CaSki}$ & No & Plasmid DNA & No & {$[48,49]$} \\
\hline & ZFN & E7 & SiHa, Hela, CaSki, S12 & Yes & Plasmid DNA & $\begin{array}{l}\text { Cationic polymer } \\
\text { (Intratumoral) }\end{array}$ & [36] \\
\hline & BEF & LCR & Hela & No & Plasmid DNA & No & [38] \\
\hline & AZP-SNase or scFokl & LCR & None & No & $\begin{array}{l}\text { Plasmid DNA, } \\
\text { Protein }\end{array}$ & No & {$[39-42,46]$} \\
\hline HTLV-1 & ZFN & LTR & C8166, S1T, ED & Yes & Plasmid DNA & No & [67] \\
\hline \multirow[t]{5}{*}{ EBV (HHV-4) } & \multirow[t]{4}{*}{ spCas9 } & $\begin{array}{l}\text { EBNA-LP, } 125 \text { bp } \\
\text { repeat, EBNA3C, } \\
\text { EBNA1, pstl repeat, } \\
\text { LMP1 }\end{array}$ & Raji & No & Plasmid DNA & No & {$[78]$} \\
\hline & & $\begin{array}{l}\text { EBNA1, oriP, miRNA } \\
\text { promoter }\end{array}$ & SNU-719 & No & Lentiviral vector & No & [79] \\
\hline & & LMP1 & EBV infected cell line & No & Plasmid DNA & No & {$[87]$} \\
\hline & & $\begin{array}{l}\text { EBNA1, oriP and W } \\
\text { repeats }\end{array}$ & C666-1 & No & Plasmid DNA & No & {$[80]$} \\
\hline & TALEN & EBNA1 & $\begin{array}{l}\text { Raji, SNU-719, SNU- } \\
265\end{array}$ & No & Plasmid DNA & No & {$[77]$} \\
\hline \multirow[t]{2}{*}{$\begin{array}{l}\text { KSHV } \\
(\mathrm{HHV}-8)\end{array}$} & \multirow[t]{2}{*}{ spCas9 } & LANA & Vero219, L1T2, BC3 & No & Adenoviral genome & $\begin{array}{l}\text { Replication-deficient } \\
\text { Ad5 } \\
\text { (Intratumoral) }\end{array}$ & {$[84]$} \\
\hline & & $\begin{array}{l}\text { K12-miR promoter } \\
\text { miR-K12-1 } \\
\text { miR-K12-9 }\end{array}$ & BCP-1, BCBL-1 & No & Plasmid DNA & No & [90] \\
\hline MCPyV & spCas9 & LT and sT & MS-1, WaGa & No & Plasmid DNA & No & [106] \\
\hline
\end{tabular}

The modalities that have been developed against their respective oncogenic viruses and targets in each study are shown. The in vitro cell lines as well as whether in vivo studies were performed are highlighted. The delivery vectors developed are indicated along with the route of administration used in vivo. The expression vector used for the different nuclease modalities are indicated

a AAV delivered gRNA to Cas9 overexpressing cell line

very promising for topical administration in early stage HPV cervical cancers, but other HPV-affected tissues, like esophageal regions, may not be readily accessible. Furthermore, late stage metastatic HPV would ideally require systemic delivery with a potential viable approach using 'stealth' lipid nanoparticles [37], but whether systemic treatment with these particles will reach all secondary sites of HPV metastasis (lymph, lung, liver, and bone marrow) remains to be determined. Furthermore, whether the 'passive targeting' of the lipid nanoparticles would effectively deliver nucleases to tumor cells in other virus-associated cancers, especially blood cancers like ATL or B-cell lymphomas, should be assessed. Importantly, plasmid DNA components were used in the majority of the discussed studies (Table 2), which may be problematic as it would express nucleases for extended periods in healthy tissue. Substituting the DNA vectors for transient components combined with lipid nanoparticles, like mRNA [123] or RNPs [124] may improve the 'druggability' of therapeutic nucleases. Lastly, CRISPR/Cas9, ZFNs, and TALENs require two components and a single module nuclease may have advantages to simplify economic scale-up and delivery, and the compact high-fidelity meganucleases 
should be considered for targeted inactivation of viral oncogenes (Fig. 1) [125].

\section{A note on $\mathrm{HBV}$ and $\mathrm{HCV}$}

HBV and hepatitis $\mathrm{C}$ virus (HCV) are carcinogenic viruses known to increase the risk of hepatocellular carcinoma (HCC), a devastating liver cancer. However, there is no evidence that antivirals will inhibit HCC growth, but rather eliminating these viruses before cancer development may reduce cancer risk [126, 127]. As viral targeting will likely not augment tumor progression, these viruses are beyond the scope of this review. However, there are extensive reviews covering innovative targeted nucleases to HBV and HCV $[128,129]$.

\section{'Hit-and-run' virally driven cancers}

As described, there are established examples of viral oncogenes contributing to tumor maintenance, pathological features, and chemoresistance and, in the context of HPV-related cervical cancers, an established state of oncogene addiction. However, it must be mentioned that there are examples where the viral components may become dispensable to the tumor phenotype. There are recent postulations for a 'hit-and-run' hypothesis suggesting that the accumulation of other genomic mutations could supersede the tumor's dependence on the viral oncogenes resulting in a virus-independent tumor (Reviewed in [130]). This virus-independence has been observed with the spontaneous loss of EBV episomes in a Burkitt's lymphoma (BL) cell line [131], or KSHV transformed cell lines that are episome negative but still tumorigenic in mice [132], and even in instances of HPV-related cancers, often considered a clear example of oncogenic addiction, known HPV18 transformed cell lines can lack HPV DNA [133]. Future studies should focus on clarifying the context and extent to which these cancers are dependent on viral elements, as this insight would allow for the cognizant application of nucleases in the treatment of virus-associated cancers. Furthermore, in situations where the viral oncogenes are completely lost and go undetected in the tumor biopsies, a 'hit-andrun' hypothesis may suggest a larger contribution of oncogenic viruses to diagnosed cancers than previously thought, which could provide a rationale for the early detection and prophylactic targeted inactivation of highrisk viral oncogenes to prevent cancer.

\section{Conclusion}

Oncogenic viruses are a global health crisis, often aggressive with poor responses to current treatments, necessitating the development of novel therapeutics (Table 2). The potential for targeted nucleases to inhibit virally driven cancers cannot be overstated as unlike many non-viral cancers these offer a critical and unique oncogene that is foreign, and are ideal targets for designer nuclease-mediated inactivation, which could permanently inactivate tumorigenic drivers while improving responses to standard chemotherapeutic regimens. Encouragingly, there are registered clinical trials using anti-HPV ZFNs, TALENs and CRISPR/Cas for local vaginal treatment (Reviewed in [10]) and, if positive effects are observed, would be a significant alternative approach to treat recurrent HPV, and provide strong support for the future development of these modalities with appropriate delivery vectors against late-stage metastatic HPV. Although there are a number of studies validating the anti-tumor effects of targeted nucleases to viral oncogenes, there is considerable challenges before these can be applied broadly in clinic such as the validation of effective anti-tumor viral targets in representative cell line models, observing anti-tumor effects in vivo in combination with viable delivery platforms, and the assessment of safety profiles. Nevertheless, designer nucleases offer a novel treatment approach that could be transformative for patients suffering for aggressive virally driven malignancies.

\section{Abbreviations}

AAV: Adeno-associated viral vector; Ad5: Adenovirus type 5; ART: Antiretroviral therapy; ATL: Adult T-cell leukemia/lymphoma; ASO: Antisense oligonucleotides; BEF: Bovine HPV E2 fused to Fokl; BL: Burkitt's lymphoma; CIN: Cervical intraepithelial neoplasia; CPP: Cell penetrating peptides; crRNA: CRISPR RNA; CRISPR/Cas: The clustered regularly interspaced short palindromic repeats with CRISPR-associated protein; DSB: Double stranded break; EBNA1: EBV nuclear antigen 1; EBV: Epstein-Barr virus; HDR: Homology directed repair; HPV: Human papillomavirus; HTLV-1: Human T-cell leukemia virus type 1; HHV: Human herpesvirus; Indel: Insertion and deletions; KSHV: Kaposi's sarcomaassociated herpesvirus; KS: Kaposi's sarcoma; LT: Large tumor antigen; LANA: Latency-associated nuclear antigen; LMP1: Latent membrane protein 1; LCR: Long control region; LTR: Long terminal repeat; MCC: Merkel cell carcinomas; MCPyV: Merkel cell polyomavirus; MiRNA: MicroRNA; MCD: Multicentric Castleman disease; NPC: Nasopharyngeal carcinoma; NHEJ: Non-homologous DNA end joining; PEL: Primary effusion lymphoma; PAM: Protospacer adjacent motif; pRb: Retinoblastoma protein; RNAi: RNA interference; RNP: Ribonucleoprotein; RVD: Repeat-variable diresidues; sT: Small tumor antigen; TALEN: Transcription activator-like effector nuclease; TracrRNA: Trans-activating RNA; TA: Tumor antigen; vcyclin: Viral cyclin; vFLIP: Viral FLIP; ZFN: Zinc finger nuclease.

\section{Acknowledgements}

Not applicable.

\section{Authors' contributions}

T.A.S and K.V.M complied and edited the manuscript. Both authors read and approved the final manuscript.

Funding

This project was supported by NIMH R01 113407-01 to KVM.

Availability of data and materials

Not applicable.

Ethics approval and consent to participate

Not applicable. 


\section{Consent for publication}

Not applicable.

\section{Competing interests}

The authors claim no competing financial interests.

Received: 11 November 2020 Accepted: 2 January 2021

Published online: 13 January 2021

\section{References}

1. Li H, Yang Y, Hong W, Huang M, Wu M, Zhao X. Applications of genome editing technology in the targeted therapy of human diseases: mechanisms, advances and prospects. Signal Transduct Target Ther. 2020;5:1.

2. Ashmore-Harris C, Fruhwirth GO. The clinical potential of gene editing as a tool to engineer cell-based therapeutics. Clin Transl Med. 2020;9:15-15.

3. Li T, Huang S, Zhao X, Wright DA, Carpenter S, Spalding MH, Weeks DP, Yang B. Modularly assembled designer TAL effector nucleases for targeted gene knockout and gene replacement in eukaryotes. Nucleic Acids Res. 2011:39:6315-25.

4. Jinek M, Chylinski K, Fonfara I, Hauer M, Doudna JA, Charpentier E. A programmable dual-RNA — guided DNA endonuclease in adaptive bacterial immunity. Science. 2012;337:816-21.

5. Cong L, Ran FA, Cox D, Lin S, Barretto R, Habib N, Hsu PD, Wu X, Jiang W, Marraffini LA, Zhang F. Multiplex genome engineering using CRISPR/ Cas systems. Science. 2013;339:819-23.

6. Nishimasu H, Ran FA, Hsu Patrick D, Konermann S, Shehata Soraya I, Dohmae N, Ishitani R, Zhang F, Nureki O. Crystal structure of Cas9 in complex with guide RNA and target DNA. Cell. 2014;156:935-49.

7. Dash PK, Kaminski R, Bella R, Su H, Mathews S, Ahooyi TM, Chen C, Mancuso P, Sariyer R, Ferrante $P$, et al. Sequential LASER ART and CRISPR treatments eliminate HIV-1 in a subset of infected humanized mice. Nature Communications. 2019:10:2753.

8. Kostyushev D, Brezgin S, Kostyusheva A, Zarifyan D, Goptar I, Chulanov V. Orthologous CRISPR/Cas9 systems for specific and efficient degradation of covalently closed circular DNA of hepatitis B virus. Cell Mol Life Sci. 2019:76:1779-94.

9. Yin H, Xue W, Anderson DG. CRISPR-Cas: a tool for cancer research and therapeutics. Nature Rev Clin Oncol. 2019;16:281-95.

10. Hirakawa MP, Krishnakumar R, Timlin JA, Carney JP, Butler KS. Gene editing and CRISPR in the clinic: current and future perspectives. Biosci Rep. 2020;40:BSR20200127

11. zur Hausen H. Viruses in human cancers. Science. 1991;254:1167-73.

12. McBride AA. Oncogenic human papillomaviruses. Philos Trans R Soc Lond B Biol Sci. 2017;372:20160273.

13. Münger K, Baldwin A, Edwards KM, Hayakawa H, Nguyen CL, Owens M, Grace M, Huh K. Mechanisms of human papillomavirus-induced oncogenesis. J Virol. 2004:78:11451.

14. Watanabe T. Adult T-cell leukemia: molecular basis for clonal expansion and transformation of HTLV-1-infected T cells. Blood. 2017;129:1071-81.

15. Yin H, Qu J, Peng Q, Gan R. Molecular mechanisms of EBV-driven cell cycle progression and oncogenesis. Med Microbiol Immunol. 2019;208:573-83.

16. Skalsky RL, Cullen BR. EBV noncoding RNAs. In: Münz C, editor. Epstein Barr virus volume 2: one herpes virus: many diseases. Cham: Springer; 2015. p. 181-217

17. Qin J, Li W, Gao S-J, Lu C. KSHV microRNAs: tricks of the devil. Trends Microbiol. 2017;25:648-61.

18. Wen KW, Damania B. Kaposi sarcoma-associated herpesvirus (KSHV): Molecular biology and oncogenesis. Cancer Lett. 2010;289:140-50.

19. Liu W, You J. Molecular mechanisms of merkel cell polyomavirus transformation and replication. Annu Rev Virol. 2020;7:289-307.

20. Plummer M, de Martel C, Vignat J, Ferlay J, Bray F, Franceschi S. Global burden of cancers attributable to infections in 2012: a synthetic analysis. Lancet Glob Health. 2016;4:e609-16.

21. Torre LA, Bray F, Siegel RL, Ferlay J, Lortet-Tieulent J, Jemal A Global cancer statistics, 2012. CA Cancer J Clin. 2015;2015(65):87-108.

22. Ho GYF, Burk RD, Klein S, Kadish AS, Chang CJ, Palan P, Basu J, Tachezy $\mathrm{R}$, Lewis R, Romney S. Persistent genital human papillomavirus infection as a risk factor for persistent cervical dysplasia. J Natl Cancer Inst. 1995;87:1365-71.

23. Jang MK, Shen K, McBride AA. Papillomavirus genomes associate with BRD4 to replicate at fragile sites in the host genome. PLoS Pathog. 2014;10:e1004117.

24. Hudson JB, Bedell MA, MCCance DJ, Laiminis LA. Immortalization and altered differentiation of human keratinocytes in vitro by the E6 and E7 open reading frames of human papillomavirus type 18. J Virol. 1990;64:519-26.

25. Arbeit JM, Münger K, Howley PM, Hanahan D. Progressive squamous epithelial neoplasia in K14-human papillomavirus type 16 transgenic mice. J Virol. 1994:68:4358.

26. Yoshinouchi M, Yamada T, Kizaki M, Fen J, Koseki T, Ikeda Y, Nishihara T, Yamato K. In vitro and in vivo growth suppression of human papillomavirus 16-positive cervical cancer cells by e6 siRNA. Mol Ther. 2003;8:762-8.

27. Zhen S, Hua L, Takahashi Y, Narita S, Liu Y-H, Li Y. In vitro and in vivo growth suppression of human papillomavirus 16-positive cervical cancer cells by CRISPR/Cas9. Biochem Biophys Res Commun. 2014:450:1422-6.

28. Kennedy EM, Kornepati AVR, Goldstein M, Bogerd HP, Poling BC, Whisnant AW, Kastan MB, Cullen BR. Inactivation of the human papillomavirus E6 or E7 gene in cervical carcinoma cells by using a bacterial CRISPR/Cas RNA-guided endonuclease. J Virol. 2014;88:11965-72.

29. Mincheva A, Gissmann L, zur Hausen H. Chromosomal integration sites of human papillomavirus DNA in three cervical cancer cell lines mapped by in situ hybridization. Med Microbiol Immunol. 1987; 176:245-56

30. Hu Z, Yu L, Zhu D, Ding W, Wang X, Zhang C, Wang L, Jiang $X$, Shen $\mathrm{H}, \mathrm{He}$ D, et al. Disruption of HPV16-E7 by CRISPR/Cas system induces apoptosis and growth inhibition in HPV16 positive human cervical cancer cells. Biomed Res Int. 2014;2014:612823.

31. Felsher DW. Oncogene addiction versus oncogene amnesia: perhaps more than just a bad habit? Can Res. 2008;68:3081.

32. Yoshiba T, Saga Y, Urabe M, Uchibori R, Matsubara S, Fujiwara H, Mizukami H. CRISPR/Cas9-mediated cervical cancer treatment targeting human papillomavirus E6. Oncol Lett. 2019;17:2197-206.

33. Bortnik V, Wu M, Julcher B, Salinas A, Nikolic I, Simpson KJ, McMillan NAJ, Idris A. Loss of HPV type 16 E7 restores CGAS-STING responses in human papilloma virus-positive oropharyngeal squamous cell carcinomas cells. J Microbiol Immunol Infect 2020.

34. Liu Y-C, Cai Z-M, Zhang X-J. Reprogrammed CRISPR-Cas9 targeting the conserved regions of HPV6/11 E7 genes inhibits proliferation and induces apoptosis in E7-transformed keratinocytes. Asian J Androl. 2016;18:475-9.

35. Hu Z, Ding W, Zhu D, Yu L, Jiang X, Wang X, Zhang C, Wang L, Ji T, Liu $D$, et al. TALEN-mediated targeting of HPV oncogenes ameliorates HPV-related cervical malignancy. J Clin Investig. 2015;125:425-36.

36. Ding W, Hu Z, Zhu D, Jiang $X$, Yu L, Wang $X$, Zhang C, Wang L, Ji T, $\mathrm{Li}$ K, et al. Zinc finger nucleases targeting the human papillomavirus E7 oncogene induce disruption and a transformed phenotype in HPV16/18-positive cervical cancer cells. Clin Cancer Res. 2014:20:6495.

37. Jubair L, Fallaha S, McMillan NAJ. Systemic delivery of CRISPR/Cas9 targeting HPV oncogenes is effective at eliminating established tumors. Mol Ther. 2019;27:2091-9.

38. Horner SM, DiMaio D. The DNA binding domain of a papillomavirus E2 protein programs a chimeric nuclease to cleave integrated human papillomavirus DNA in HeLa cervical carcinoma cells. J Virol. 2007:81:6254.

39. Mino T, Hatono T, Matsumoto N, Mori T, Mineta Y, Aoyama Y, Sera T. Inhibition of DNA replication of human papillomavirus by artificial zinc finger proteins. J Virol. 2006;80:5405.

40. Mino T, Mori T, Aoyama Y, Sera T. Gene- and protein-delivered zinc finger-staphylococcal nuclease hybrid for inhibition of DNA replication of human papillomavirus. PLoS ONE. 2013:8:e56633.

41. Mino T, Aoyama Y, Sera T. Efficient double-stranded DNA cleavage by artificial zinc-finger nucleases composed of one zinc-finger protein and a single-chain Fokl dimer. J Biotechnol. 2009;140:156-61. 
42. Mino T, Mori T, Aoyama Y, Sera T. Inhibition of DNA replication of human papillomavirus by using zinc finger-single-chain foki dimer hybrid. Mol Biotechnol. 2014;56:731-7.

43. Gaj T, Guo J, Kato Y, Sirk SJ, Barbas CF. Targeted gene knockout by direct delivery of zinc-finger nuclease proteins. Nat Methods. 2012;9:805-7.

44. Ho A, Schwarze SR, Mermelstein SJ, Waksman G, Dowdy SF. Synthetic protein transduction domains: enhanced transduction potential in vitro and in vivo. Can Res. 2001;61:474-7.

45. Hu J, Lou Y, Wu F. Improved intracellular delivery of polyarginine peptides with cargoes. J Phys Chem B. 2019;123:2636-44.

46. Mino T, Mori T, Aoyama Y, Sera T. Cell-permeable artificial zinc-finger proteins as potent antiviral drugs for human papillomaviruses. Adv Virol. 2008;153:1291.

47. Inturi R, Jemth P. CRISPR/Cas9-based inactivation of human papillomavirus oncogenes E6 and E7 induces senescence in cervical cancer cells. bioRxiv 2020;2020.2004.2016.044446.

48. Shankar S, Prasad D, Sanawar R, Das AV, Pillai MR. TALEN based HPV-E7 editing triggers necrotic cell death in cervical cancer cells. Sci Rep. 2017;7:5500

49. Shankar S, Sreekumar A, Prasad D, Das AV, Pillai MR. Genome editing of oncogenes with ZFNs and TALENs: caveats in nuclease design. Cancer Cell Int. 2018:18:169.

50. Katsuya H, Ishitsuka K, Utsunomiya A, Hanada S, Eto T, Moriuchi Y, Saburi Y, Miyahara M, Sueoka E, Uike N, et al. Treatment and survival among 1594 patients with ATL. Blood. 2015;126:2570-7.

51. Takeda S, Maeda M, Morikawa S, Taniguchi Y, Yasunaga J-I, Nosaka K, Tanaka Y, Matsuoka M. Genetic and epigenetic inactivation of tax gene in adult T-cell leukemia cells. Int J Cancer. 2004;109:559-67.

52. Koiwa T, Hamano-Usami A, Ishida T, Okayama A, Yamaguchi K, Kamihira S, Watanabe T. 5'-long terminal repeat-selective CpG methylation of latent human T-cell leukemia virus type 1 provirus in vitro and in vivo. J Virol. 2002;76:9389-97.

53. Gaudray G, Gachon F, Basbous J, Biard-Piechaczyk M, Devaux C, Mesnard J-M. The complementary strand of the human T-cell leukemia virus type 1 RNA genome encodes a bZIP transcription factor that down-regulates viral transcription. J Virol. 2002;76:12813.

54. Kataoka K, Nagata Y, Kitanaka A, Shiraishi Y, Shimamura T, Yasunaga J-I, Totoki Y, Chiba K, Sato-Otsubo A, Nagae G, et al. Integrated molecular analysis of adult T cell leukemia/lymphoma. Nat Genet. 2015:47:1304-15.

55. Enose-Akahata Y, Abrams A, Massoud R, Bialuk I, Johnson KR, Green PL, Maloney EM, Jacobson S. Humoral immune response to HTLV-1 basic leucine zipper factor (HBZ) in HTLV-1-infected individuals. Retrovirology. 2013;10:19.

56. Mitobe Y, Yasunaga J-I, Furuta R, Matsuoka M. HTLV-1 bZIP factor RNA and protein impart distinct functions on T-cell proliferation and survival. Cancer Res. 2015:75:4143-52.

57. Satou Y, Yasunaga J-I, Yoshida M, Matsuoka M. HTLV-I basic leucine zipper factor gene mRNA supports proliferation of adult T cell leukemia cells. Proc Natl Acad Sci USA. 2006;103:720-5.

58. Hagiya K, Yasunaga J-I, Satou Y, Ohshima K, Matsuoka M. ATF3, an HTLV-1 bZip factor binding protein, promotes proliferation of adult T-cell leukemia cells. Retrovirology. 2011:8:19.

59. Ma G, Yasunaga J, Fan J, Yanagawa S, Matsuoka M. HTLV-1 bZIP factor dysregulates the Wnt pathways to support proliferation and migration of adult T-cell leukemia cells. Oncogene. 2013;32:4222-30.

60. Sugata K, Yasunaga J-I, Kinosada H, Mitobe Y, Furuta R, Mahgoub M, Onishi C, Nakashima K, Ohshima K, Matsuoka M. HTLV-1 viral factor HBZ induces CCR4 to promote T-cell migration and proliferation. Cancer Res. 2016;76:5068

61. Xiang J, Rauch DA, Huey DD, Panfil AR, Cheng X, Esser AK, Su X, Harding JC, XU Y, Fox GC, et al. HTLV-1 viral oncogene HBZ drives bone destruction in adult T cell leukemia. JCl insight. 2019;4:e128713.

62. Tanaka-Nakanishi A, Yasunaga J-I, Takai K, Matsuoka M. HTLV-1 bZIP factor suppresses apoptosis by attenuating the function of FoxO3a and altering its localization. Cancer Res. 2014:74:188.

63. Kuhlmann A-S, Villaudy J, Gazzolo L, Castellazzi M, Mesnard J-M, Duc Dodon M. HTLV-1 HBZ cooperates with JunD to enhance transcription of the human telomerase reverse transcriptase gene (hTERT). Retrovirology. 2007;4:92
64. Vernin C Thenoz M Pinatel C Gessain A Gout O, Delfau-Larue M-H, Nazaret N, Legras-Lachuer C, Wattel E, Mortreux F. HTLV-1 bZIP factor HBZ promotes cell proliferation and genetic instability by activating OncomiRs. Can Res. 2014;74:6082.

65. Higuchi Y, Yasunaga J-I, Mitagami Y, Tsukamoto H, Nakashima K, Ohshima K, Matsuoka M. HTLV-1 induces T cell malignancy and inflammation by viral antisense factor-mediated modulation of the cytokine signaling. Proc Natl Acad Sci USA. 2020;117:13740-9.

66. Arnold J, Zimmerman B, Li M, Lairmore MD, Green PL. Human T-cell leukemia virus type-1 antisense-encoded gene, $\mathrm{Hbz}$, promotes T-lymphocyte proliferation. Blood. 2008;112:3788-97.

67. Tanaka A, Takeda S, Kariya R, Matsuda K, Urano E, Okada S, Komano J. A novel therapeutic molecule against HTLV-1 infection targeting provirus. Leukemia. 2013:27:1621-7.

68. Nguyen HQ, Magaret AS, Kitahata MM, Van Rompaey SE, Wald A, Casper C. Persistent Kaposi sarcoma in the era of highly active antiretroviral therapy: characterizing the predictors of clinical response. AIDS (London, England). 2008;22:937-45.

69. Sinfield RL, Molyneux EM, Banda K, Borgstein E, Broadhead R, Hesseling $\mathrm{P}$, Newton $\mathrm{R}$, Casabonne D, Mkandawire N, Nkume $\mathrm{H}$, et al. Spectrum and presentation of pediatric malignancies in the HIV era: experience from Blantyre, Malawi 1998-2003. Pediatr Blood Cancer. 2007:48:515-20.

70. Tang Y, Luo C, Cheng A, Lu S, Xu J, Fu T, Gan R. Expression of latent membrane proteins in Epstein-Barr virus-transformed lymphocytes in vitro. Mol Med Rep. 2014;10:1117-21.

71. Kennedy G, Komano J, Sugden B. Epstein-Barr virus provides a survival factor to Burkitt's lymphomas. Proc Natl Acad Sci USA. 2003:100:14269-74.

72. Wilson JB, Manet E, Gruffat H, Busson P, Blondel M, Fahraeus R. EBNA1: oncogenic activity, immune evasion and biochemical functions provide targets for novel therapeutic strategies against Epstein-Barr virusassociated cancers. Cancers. 2018;10:109.

73. Li N, Thompson S, Schultz DC, Zhu W, Jiang H, Luo C, Lieberman PM Discovery of selective inhibitors against EBNA1 via high throughput in silico virtual screening. PLoS ONE. 2010;5:e10126.

74. Tempera I, De Leo A, Kossenkov AV, Cesaroni M, Song H, Dawany $\mathrm{N}$, Showe L, Lu F, Wikramasinghe $\mathrm{P}$, Lieberman PM. Identification of MEF2B, EBF1, and IL6R as direct gene targets of Epstein-Barr virus (EBV) nuclear antigen 1 critical for EBV-infected B-lymphocyte survival. J Virol. 2016;90:345.

75. Yin Q, Flemington EK. siRNAs against the Epstein Barr virus latency replication factor, EBNA1, inhibit its function and growth of EBV-dependent tumor cells. Virology. 2006;346:385-93.

76. Hong M, Murai Y, Kutsuna T, Takahashi H, Nomoto K, Cheng C-M, Ishizawa S, Zhao Q-L, Ogawa R, Harmon BV, et al. Suppression of Epstein-Barr nuclear antigen 1 (EBNA1) by RNA interference inhibits proliferation of EBV-positive Burkitt's lymphoma cells. J Cancer Res Clin Oncol. 2006:132:1-8.

77. Noh K-W, Park J, Kang M-S. Targeted disruption of EBNA1 in EBVinfected cells attenuated cell growth. BMB reports. 2016:49:226-31.

78. Wang J, Quake SR. RNA-guided endonuclease provides a therapeutic strategy to cure latent herpesviridae infection. Proc Natl Acad Sci USA 2014;111:13157.

79. van Diemen FR, Kruse EM, Hooykaas MJG, Bruggeling CE, Schürch AC, van Ham PM, Imhof SM, Nijhuis M, Wiertz EJHJ, Lebbink RJ. CRISPR/ Cas9-mediated genome editing of herpesviruses limits productive and latent infections. PLoS Pathog. 2016;12:e1005701.

80. Yuen K-S, Wang Z-M, Wong N-HM, Zhang Z-Q, Cheng T-F, Lui W-Y, Chan C-P, Jin D-Y. Suppression of Epstein-Barr virus DNA load in latently infected nasopharyngeal carcinoma cells by CRISPR/Cas9. Virus Res. 2018:244:296-303.

81. Friborg J, Kong W-P, Hottiger MO, Nabel GJ. p53 inhibition by the LANA protein of KSHV protects against cell death. Nature. 1999:402:889-94.

82. Radkov SA, Kellam P, Boshoff C. The latent nuclear antigen of Kaposi sarcoma-associated herpesvirus targets the retinoblastoma-E2F pathway and with the oncogene Hras transforms primary rat cells. Nat Med. 2000;6:1121-7.

83. Godfrey A, Anderson J, Papanastasiou A, Takeuchi Y, Boshoff C. Inhibiting primary effusion lymphoma by lentiviral vectors encoding short hairpin RNA. Blood. 2005;105:2510-8. 
84. Tso FY, West JT, Wood C. Reduction of Kaposi's sarcoma-associated herpesvirus latency using CRISPR-Cas9 to edit the latency-associated nuclear antigen gene. J Virol. 2019;93:e02183-e12118.

85. BeltCappellino A, Majerciak V, Lobanov A, Lack J, Cam M, Zheng Z-M. CRISPR/Cas9-mediated knockout and inversion of the ORF57 gene from all copies of the Kaposi sarcoma-associated herpesvirus genome in BCBL-1 cells. J Virol. 2019:93:e00628-e1619.

86. Mei Y-P, Zhou J-M, Wang Y, Huang H, Deng R, Feng G-K, Zeng Y-X, Zhu $X-F$. Silencing of LMP1 induces cell cycle arrest and enhances chemosensitivity through inhibition of AKT signaling pathway in EBV-positive nasopharyngeal carcinoma cells. Cell Cycle. 2007;6:1379-85.

87. Huo H, Hu G. CRISPR/Cas9-mediated LMP1 knockout inhibits EpsteinBarr virus infection and nasopharyngeal carcinoma cell growth. Infect Agents Cancer. 2019;14:30-30

88. Dittmer D, Lagunoff M, Renne R, Staskus K, Haase A, Ganem D. A cluster of latently expressed genes in Kaposi's sarcoma-associated herpesvirus. J Virol. 1998;72:8309-15.

89. Bigi R, Landis JT, An H, Caro-Vegas C, Raab-Traub N, Dittmer DP. EpsteinBarr virus enhances genome maintenance of Kaposi sarcoma-associated herpesvirus. Proc Natl Acad Sci USA. 2018;115:E11379.

90. Liang Z, Qin Z, Riker Al, Xi Y. CRISPR/Cas9 ablating viral microRNA promotes lytic reactivation of Kaposi's sarcoma-associated herpesvirus. Biochem Biophys Res Commun. 2020;533:1400-5.

91. Seto E, Moosmann A, Grömminger S, Walz N, Grundhoff A, Hammerschmidt W. Micro RNAs of Epstein-Barr virus promote cell cycle progression and prevent apoptosis of primary human B cells. PLoS Pathog. 2010;6:e1001063.

92. Kim DN, Seo MK, Choi H, Kim SY, Shin HJ, Yoon A-R, Tao Q, Rha SY, Lee SK. Characterization of naturally Epstein-Barr virus-infected gastric carcinoma cell line YCCEL1. J Gen Virol. 2013;94:497-506.

93. Feng $H$, Shuda M, Chang Y, Moore PS. Clonal integration of a polyomavirus in human merkel cell carcinoma. Science. 2008;319:1096-100.

94. Jensen F, Koprowski H, Ponten JA. Rapid transformation of human fibroblast cultures by simian virus. Proc Natl Acad Sci USA. 1963;50:343-8.

95. Bhatia S, Storer BE, lyer JG, Moshiri A, Parvathaneni U, Byrd D, Sober AJ, Sondak VK, Gershenwald JE, Nghiem P. Adjuvant radiation therapy and chemotherapy in Merkel cell carcinoma: survival analyses of 6908 cases from the National Cancer Data Base. J Natl Cancer Inst. 2016;108:042.

96. Paulson KG, Park SY, Vandeven NA, Lachance K, Thomas H, Chapuis AG, Harms KL, Thompson JA, Bhatia S, Stang A, Nghiem P. Merkel cell carcinoma: current US incidence and projected increases based on changing demographics. J Am Acad Dermatol. 2018;78(457-463):e452.

97. Shuda M, Arora R, Kwun HJ, Feng H, Sarid R, Fernández-Figueras M-T, Tolstov Y, Gjoerup O, Mansukhani MM, Swerdlow SH, et al. Human Merkel cell polyomavirus infection I. MCVT antigen expression in Merkel cell carcinoma, lymphoid tissues and lymphoid tumors. Int J Cancer. 2009;125:1243-9.

98. Cheng J, Rozenblatt-Rosen O, Paulson KG, Nghiem P, DeCaprio JA. Merkel cell polyomavirus large T antigen has growth-promoting and inhibitory activities. J Virol. 2013;87:6118.

99. Shuda M, Feng H, Kwun HJ, Rosen ST, Gjoerup O, Moore PS, Chang Y. T antigen mutations are a human tumor-specific signature for Merkel cell polyomavirus. Proc Natl Acad Sci USA. 2008;105:16272-7.

100. Kwun Hyun J, Shuda M, Feng H, Camacho Carlos J, Moore Patrick S, Chang Y. Merkel cell polyomavirus small T antigen controls viral replication and oncoprotein expression by targeting the cellular ubiquitin ligase SCFFbw7. Cell Host Microbe. 2013;14:125-35.

101. Shuda M, Kwun HJ, Feng H, Chang Y, Moore PS. Human Merkel cell polyomavirus small T antigen is an oncoprotein targeting the 4E-BP1 translation regulator. J Clin Investig. 2011;121:3623-34.

102. Park DE, Cheng J, Berrios C, Montero J, Cortés-Cros M, Ferretti S, Arora R, Tillgren ML, Gokhale PC, DeCaprio JA. Dual inhibition of MDM2 and MDM4 in virus-positive Merkel cell carcinoma enhances the p53 response. Proc Natl Acad Sci USA. 2019:116:1027-32.

103. Verhaegen ME, Mangelberger D, Harms PW, Vozheiko TD, Weick JW, Wilbert DM, Saunders TL, Ermilov AN, Bichakjian CK, Johnson TM, et al. Merkel cell polyomavirus small T antigen is oncogenic in transgenic mice. J Invest Dermatol. 2015;135:1415-24.

104. Houben R, Shuda M, Weinkam R, Schrama D, Feng H, Chang Y, Moore PS, Becker JC. Merkel cell polyomavirus-infected merkel cell carcinoma cells require expression of viral T antigens. J Virol. 2010;84:7064-72.
105. Houben R, Adam C, Baeurle A, Hesbacher S, Grimm J, Angermeyer S, Henzel K, Hauser S, Elling R, Bröcker E-B, et al. An intact retinoblastoma protein-binding site in Merkel cell polyomavirus large T antigen is required for promoting growth of Merkel cell carcinoma cells. Int J Cancer. 2012;130:847-56.

106. Temblador A, Topalis D, Andrei G, Snoeck R. CRISPR/Cas9 editing of the polyomavirus tumor antigens inhibits Merkel cell carcinoma growth in vitro. Cancers (Basel). 2019;11:1260.

107. Polakowski N, Terol M, Hoang K, Nash I, Laverdure S, Gazon H, Belrose G, Mesnard J-M, Césaire R, Péloponèse J-M, Lemasson I. HBZ Stimulates brain-derived neurotrophic factor/TrkB autocrine/paracrine signaling to promote survival of human T-cell leukemia virus type 1-infected T cells. J Virol. 2014;88:13482-94.

108. Arora R, Shuda M, Guastafierro A, Feng H, Toptan T, Tolstov Y, Normolle $D$, Vollmer LL, Vogt A, Dömling A, et al. Survivin is a therapeutic target in Merkel cell carcinoma. Sci Transl Med. 2012;4:133ra156.

109. Guo L, Tang M, Yang L, Xiao L, Bode AM, Li L, Dong Z, Cao Y. EpsteinBarr virus oncoprotein LMP1 mediates survivin upregulation by p53 contributing to G1/S cell cycle progression in nasopharyngeal carcinoma. Int J Mol Med. 2012;29:574-80.

110. Lu J, Verma SC, Murakami M, Cai Q, Kumar P, Xiao B, Robertson ES. Latency-associated nuclear antigen of Kaposi's sarcoma-associated herpesvirus (KSHV) upregulates survivin expression in KSHV-associated B-lymphoma cells and contributes to their proliferation. J Virol. 2009;83:7129-41.

111. Zhen S, Lu J-J, Wang L-J, Sun X-M, Zhang J-Q, Li X, Luo W-J, Zhao L. In vitro and in vivo synergistic therapeutic effect of cisplatin with human papillomavirus16 E6/E7 CRISPR/Cas9 on cervical cancer cell line. Transl Oncol. 2016;9:498-504.

112. Quint W, Jenkins D, Molijn A, Struijk L, van de Sandt M, Doorbar J, Mols J, Van Hoof C, Hardt K, Struyf F, Colau B. One virus, one lesion-individual components of CIN lesions contain a specific HPV type. J Pathol. 2012;227:62-71.

113. Wang G, Zhao N, Berkhout B, Das AT. CRISPR-Cas9 Can inhibit HIV-1 replication but NHEJ repair facilitates virus escape. Mol Ther. 2016;24:522-6.

114. Lebbink RJ, de Jong DCM, Wolters F, Kruse EM, van Ham PM, Wiertz EJHJ, Nijhuis M. A combinational CRISPR/Cas9 gene-editing approach can halt HIV replication and prevent viral escape. Sci Rep. 2017:7:41968.

115. Gao Z, Fan M, Das AT, Herrera-Carrillo E, Berkhout B. Extinction of all infectious HIV in cell culture by the CRISPR-Cas12a system with only a single crRNA. Nucleic Acids Res. 2020;48:5527-39.

116. Gessain A, Mahieux R, de Thé G. Genetic variability and molecular epidemiology of human and simian T cell leukemia/lymphoma virus type I. J Acquir Immune Defic Syndr Hum Retrovirol. 1996;13:S132-45.

117. Zetsche B, Heidenreich M, Mohanraju P, Fedorova I, Kneppers J, DeGennaro EM, Winblad N, Choudhury SR, Abudayyeh OO, Gootenberg JS, et al. Multiplex gene editing by CRISPR-Cpf1 using a single crRNA array. Nat Biotechnol. 2017;35:31-4.

118. Naeem M, Majeed S, Hoque MZ, Ahmad I. Latest developed strategies to minimize the off-target effects in CRISPR-Cas-mediated genome editing. Cells. 2020;9:1608.

119. Kim D, Luk K, Wolfe SA, Kim J-S. Evaluating and enhancing target specificity of gene-editing nucleases and deaminases. Annu Rev Biochem. 2019;88:191-220.

120. Ran FA, Cong L, Yan WX, Scott DA, Gootenberg JS, Kriz AJ, Zetsche B, Shalem O, Wu X, Makarova KS, et al. In vivo genome editing using Staphylococcus aureus Cas9. Nature. 2015;520:186-91.

121. Kim E, Koo T, Park SW, Kim D, Kim K, Cho H-Y, Song DW, Lee KJ, Jung $\mathrm{MH}, \mathrm{Kim} \mathrm{S}$, et al. In vivo genome editing with a small Cas9 orthologue derived from Campylobacter jejuni. Nat Commun. 2017;8:14500.

122. Pausch P, Al-Shayeb B, Bisom-Rapp E, Tsuchida CA, Li Z, Cress BF, Knott GJ, Jacobsen SE, Banfield JF, Doudna JA. CRISPR-Cas $\Phi$ from huge phages is a hypercompact genome editor. Science. 2020;369:333-7.

123. Yin H, Song C-Q, Suresh S, Wu Q, Walsh S, Rhym LH, Mintzer E, Bolukbasi MF, Zhu LJ, Kauffman K, et al. Structure-guided chemical modification of guide RNA enables potent non-viral in vivo genome editing. Nat Biotechnol. 2017;35:1179-87.

124. Wei T, Cheng Q, Min Y-L, Olson EN, Siegwart DJ. Systemic nanoparticle delivery of CRISPR-Cas9 ribonucleoproteins for effective tissue specific genome editing. Nat Commun. 2020;11:3232. 
125. Ousterout DG, Gersbach CA. The Development of TALE nucleases for biotechnology. Methods Mol Biol. 2016;1338:27-42.

126. Virzì A, Roca Suarez AA, Baumert TF, Lupberger J. Oncogenic signaling induced by HCV infection. Viruses. 2018;10:538.

127. Tu T, Budzinska MA, Shackel NA, Urban S. HBV DNA integration: molecular mechanisms and clinical implications. Viruses. 2017;9:75.

128. Moyo B, Bloom K, Scott T, Ely A, Arbuthnot P. Advances with using CRISPR/Cas-mediated gene editing to treat infections with hepatitis $B$ virus and hepatitis C virus. Virus Res. 2018;244:311-20.

129. Bloom K, Maepa MB, Ely A, Arbuthnot P. Gene therapy for chronic HBV_can we eliminate cccDNA? Genes. 2018;9:207.

130. Ferreira DA, Tayyar Y, Idris A, McMillan NAJ. A "hit-and-run" affair-A possible link for cancer progression in virally driven cancers. Biochim Biophys Acta Rev Cancer. 2021;1875:188476.

131. Shimizu N, Tanabe-Tochikura A, Kuroiwa Y, Takada K. Isolation of Epstein-Barr virus (EBV)-negative cell clones from the EBV-positive
Burkitt's lymphoma (BL) line Akata: malignant phenotypes of BL cells are dependent on EBV. J Virol. 1994;68:6069-73.

132. Naipauer J, Salyakina D, Journo G, Rosario S, Williams S, Abba M, Shamay M, Mesri EA. High-throughput sequencing analysis of a "hit and run" cell and animal model of KSHV tumorigenesis. PLoS Pathog. 2020;16:e1008589.

133. Iwasaka T, Hayashi Y, Yokoyama M, Hara K, Matsuo N, Sugimori H. "Hit and run" oncogenesis by human papillomavirus type 18 DNA. Acta Obstet Gynecol Scand. 1992;71:219-23.

\section{Publisher's Note}

Springer Nature remains neutral with regard to jurisdictional claims in published maps and institutional affiliations.
Ready to submit your research? Choose BMC and benefit from:

- fast, convenient online submission

- thorough peer review by experienced researchers in your field

- rapid publication on acceptance

- support for research data, including large and complex data types

- gold Open Access which fosters wider collaboration and increased citations

- maximum visibility for your research: over $100 \mathrm{M}$ website views per year

At BMC, research is always in progress.

Learn more biomedcentral.com/submissions 